\title{
Enhanced Disease Resistance Caused by BRI1 Mutation Is Conserved Between Brachypodium distachyon and Barley (Hordeum vulgare)
}

\author{
R. Goddard, A. Peraldi, C. Ridout, and P. Nicholson \\ Department of Crop Genetics, John Innes Centre, Colney Lane, Norwich, NR4 7UH, U.K.
}

Submitted 7 March 2014. Accepted 8 June 2014.

\begin{abstract}
This study investigated the impact of brassinosteroid (BR)insensitive 1 (BRI1) mutation, the main receptor of $B R$ in both Brachypodium distachyon and barley, on disease resistance against a range of fungal pathogens of cereals exhibiting different trophic lifestyles. Results presented here show that i) disruption of BRI1 has pleiotropic effects on disease resistance in addition to affecting plant development. BR signaling functions antagonistically with mechanisms of disease resistance that are effective against a broad range of cereal pathogens. ii) Disruption of BRI1 results in increased disease resistance against necrotrophic and hemibiotrophic pathogens that exhibit only a marginal asymptomatic phase but has no effect on biotrophic pathogens or those with a prolonged asymptomatic phase, and iii) disruption of BRI1 has a similar effect on disease resistance in $B$. distachyon and barley, indicating that defense mechanisms are conserved between these species. This work presents the first evidence for conservation of disease resistance mechanisms between the model species $B$. distachyon and the cereal crop barley and validates $B$. distachyon for undertaking model-to-crop translation studies of disease resistance.
\end{abstract}

Phytohormones play critical roles in the regulation of plant responses to biotic and abiotic stresses. The hormones salicylic acid (SA), ethylene (ET), and jasmonic acid (JA) are considered to be the classical core of phytohormones associated with resistance to pathogens. SA production and signaling is generally considered to play a predominant role in resistance to biotrophic pathogens while JA/ET is considered to be more important in resistance toward necrotrophic pathogens and insects (Glazebrook 2005; Kliebenstein and Rowe 2008). However, recent evidence suggests a more complex picture, where growthpromoting phytohormones can greatly modulate the outcome of pathogen infection (Robert-Seilaniantz et al. 2011). Brassinosteroids (BR) are plant steroid hormones regulating a wide range of developmental and physiological processes such as cell

R. Goddard and A. Peraldi contributed equally to the production of this work.

Corresponding authors: R. Goddard; E-mail: rachel.goddard@jic.ac.uk; and A. Peraldi; E-mail: antoine.peraldi@jic.ac.uk

* The $\boldsymbol{e}$-Xtra logo stands for "electronic extra" and indicates that two supplementary figures are published online and that Figures 1, 2, 4, 5, and 6 appear in color online.

(C) 2014 The American Phytopathological Society elongation, vascular differentiation, root growth, responses to light, resistance to stresses, and senescence (Kim and Wang 2010). The molecular components involved in the perception, transduction, and transcriptional response to the BR signal have been deciphered during the past decade using genetic and chemical approaches (Zhu et al. 2013). Emerging evidence suggests that $\mathrm{BR}$ are also involved in the regulation of plant defense responses (Bari and Jones 2009). Work in Arabidopsis thaliana has shown that BR signaling acts antagonistically with pathogen-associated molecular pattern (PAMP)-triggered immunity (PTI) (Albrecht et al. 2012; Belkhadir et al. 2012). Lozano-Durán and colleagues (2013) later showed that BRmediated suppression of immune signaling requires expression of BZR1, one of two major BR-activated transcription factors in Arabidopsis, which induces expression of several WRKY transcription factors that negatively control early immune response. An antagonistic relationship between BR and PTI signaling has also been demonstrated in rice, where Pythium graminicola, a pathogenic oomycete of roots, exploits endogenous BR as virulence factors for host colonization (De Vleesschauwer et al. 2012). These authors showed that the immunosuppressive effect of BR is, at least partially, due to negative cross-talk with SA and gibberellic acid (GA) pathways. In addition, Nahar and colleagues (2013) showed that BR can suppress rice defense mechanisms against the root-knot nematode Meloidogyne graminicola, at least partially through negative cross-talk with the JA-signaling pathway.

The main BR receptor is known as BR-insensitive 1 (BRI1) (Nam and Li 2002). Barley (Hordeum vulgare) semidwarf Japanese (Hvbril) lines, known as "uzu", are unresponsive to exogenous application of BR (Honda et al. 2003), due to the presence of a spontaneous single-nucleotide substitution in a conserved region of the kinase domain of the HvBRIl gene (Supplementary Fig. S1) (Chono et al. 2003). The effect of such a mutation on disease resistance to a range of fungal pathogens is as yet unknown.

Research into disease resistance in grass (cereal) crop species such as wheat and barley is often difficult and time consuming because of their relatively large size and long life cycles. Genetic analysis is also impaired by the size and complexity of cereal genomes, particularly those of polyploid species such as wheat (Vain 2011). In recent years, Brachypodium distachyon has been established as a powerful tool for comparative genomics among grasses due to its many highly attractive features as a model system. $B$. distachyon has a short stature and a rapid life-cycle ( 8 to 10 weeks), and the $\mathrm{Bd} 21$ accession has a small (272 Mbp), diploid, fully sequenced genome (International Brachypodium Initiative 2010). Most importantly, the close phylogenetic relationship between $B$. distachyon and 
temperate cereals and the high degree of gene synteny with wheat (Triticum aestivum) and barley makes it an ideal model for comparative genomics (Huo et al. 2009). A growing number of resources have been developed to facilitate functional genomic studies of important traits in B. distachyon (chemical, T-DNA, and TILLING mutant collections) (Bragg et al. 2012; Dalmais et al. 2013; Vain et al. 2008). We recently characterized a $B$. distachyon mutant from the BrachyTAG collection (line BdAA900), containing a T-DNA insertion in the $5^{\prime}$ untranslated region of the Bradi2 $g 48280$ gene, 9 nucleotides upstream of the translation start signal (Thole et al. 2012). The Bradi2g48280 gene product shares $90 \%$ amino acid identity with HvBRI1. B. distachyon plants homozygous for the T-DNA insert (Bdbril) display a severely dwarfed phenotype, contorted foliar and floral tissues, and etiolated leaf segments are unresponsive to BR treatment in the leaf unrolling assay (Thole et al. 2012).

The availability of both barley and $B$. distachyon mutant lines impaired in BR signaling and mutated in the same gene (BRI1) allows investigation into the functional conservation of disease resistance mechanisms between $B$. distachyon and barley.

B. distachyon has also been demonstrated to form compatible interactions with a number of major pathogens of small-grain cereals (Barbieri et al. 2012; Draper et al. 2001; Peraldi et al. 2011, 2013; Routledge et al. 2004). This permits investigation of the response of both barley and $B$. distachyon bril lines to a range of economically important pathogens exhibiting different infection strategies, trophic lifestyles, and tissue compatibility (Table 1). Rice blast, caused by Magnaporthe oryzae is a hemibiotrophic pathogen with a brief biotrophic phase characterized by the development of haustoria within host cells (Parker et al. 2008). M. oryzae can also infect other cereals, including wheat and barley (Jarosch et al. 2003; Urashima et al. 2004). Ramularia leaf spot (RLS) of barley is caused by Ramularia collocygni, a hemibiotrophic fungus with a very prolonged endophytic phase of asymptomatic, intercellular colonization (Stabentheiner et al. 2009). Oculimacula spp. Oculimacula yallundae and $O$. acuformis both cause eyespot of wheat, barley, and rye. Unlike $O$. acuformis, $O$. yallundae exhibits a brief initial asymptomatic phase of infection before colonizing necrotrophically (Blein et al. 2009). We have recently demonstrated that $R$. collo-cygni and Oculimacula spp. can infect B. distachyon with symptoms similar to those in barley and wheat (Peraldi et al. 2013). Several Fusarium spp., including Fusarium culmorum, can infect the roots, stem bases, and heads of cereals, with the mode of infection dependent on tissue. Fusarium head blight (FHB) is an economically devastating disease due to the production of mycotoxins such as deoxynivalenol (DON) by the fungus that contaminate the grain (Bottalico and Perrone 2002). F. culmorum can also infect vegetative tissues (i.e., roots and stem bases), causing root rot (FRR) and crown rot (FCR), respectively (Miedaner 1997). F. culmorum was also demonstrated to successfully infect all tissues of $B$. distachyon, and resulting symptoms mirrored closely those developing on wheat (Peraldi et al. 2011). Take-all is a serious disease of wheat, barley, and triticale, caused by the necrotrophic pathogen Gaeumannomyces graminis var. tritici (G. graminis). Blumeria graminis is an obligate biotrophic pathogen that causes powdery mildew. B. grami-
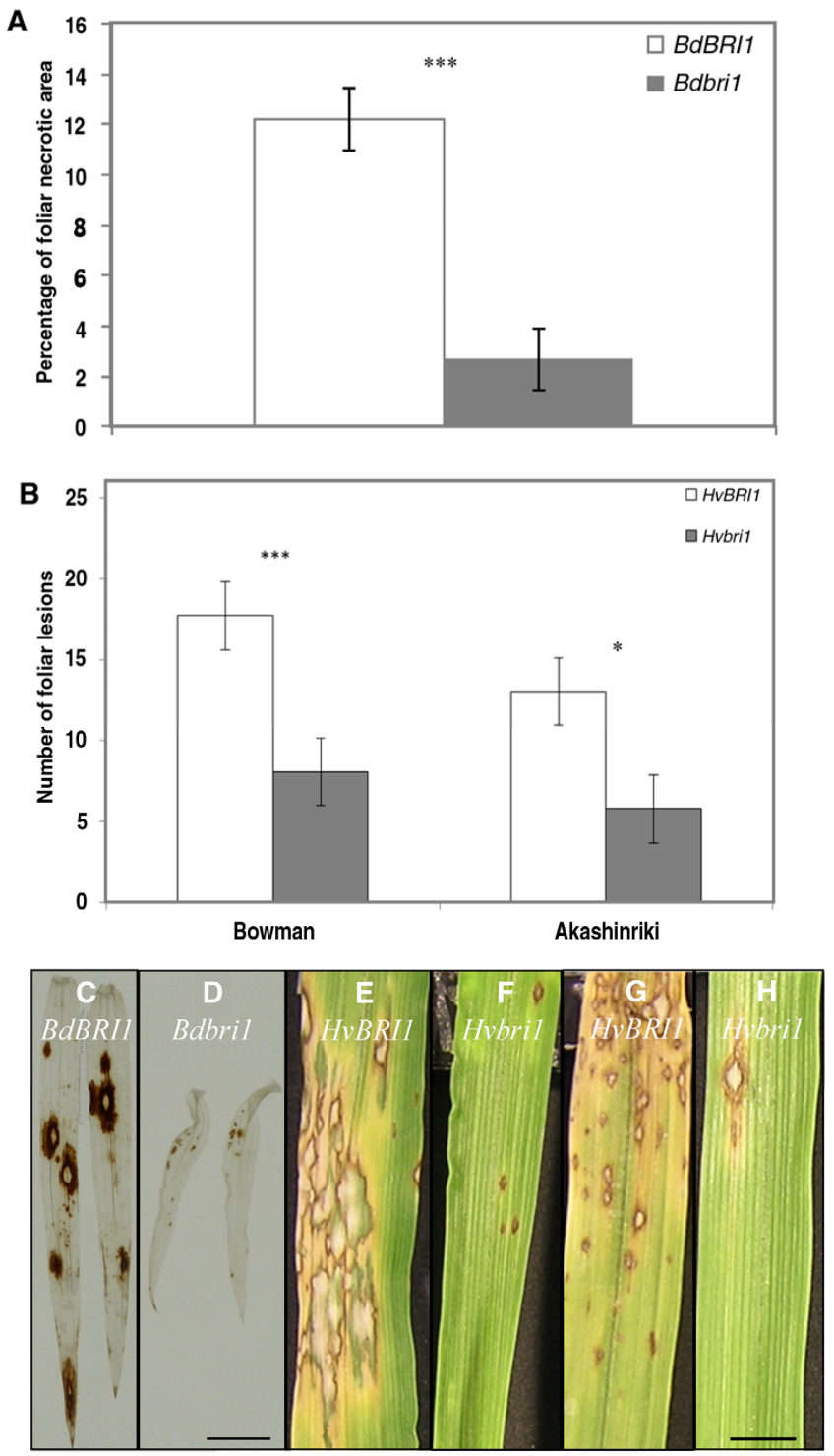

Fig. 1. Blast symptoms on leaves of Brachypodium distachyon and barley. A, Percentage of foliar necrotic area on BdBRII and Bdbril leaves, 10 days following Magnaporthe oryzae spray infection. Error bars indicate standard errors of data from 36 observations. B, Number of foliar lesions on HvBRII and Hvbril leaves, 6 days following spray infection with M. oryzae. Error bars indicate standard errors of data from 30 to 40 observations. Images of C, BdBRII and D, Bdbril cleared leaves 10 days postinoculation (dpi). Images of Bowman $\mathbf{E}, H v B R I I$ and $\mathbf{F}, H v b r i l$ and Akashinriki G, HvBRII and $\mathbf{H}, B d b r i l$ leaves, 6 dpi. *** and * indicate $P$ value $<0.001$ and 0.05 , respectively. $P$ values were obtained by Student's $t$ test analysis.

Table 1. Tissue compatibility and trophic lifestyle of the major cereal pathogens used in this study

\begin{tabular}{|c|c|c|c|}
\hline Pathogen & Tissue & Trophic lifestyle & Reference \\
\hline Blumeria graminis f. sp. hordei & Foliar & Biotroph & Both et al. 2005 \\
\hline \multirow[t]{3}{*}{ Fusarium culmorum } & Floral & Hemibiotroph (short biotrophic stage) & Brown et al. 2010 \\
\hline & Root & Necrotroph & Beccari et al. 2011 \\
\hline & Stem base & Necrotroph & Beccari et al. 2011; Chen et al. 2013 \\
\hline Gaeumannomyces graminis var. tritici & Root & Necrotroph & Freeman and Ward 2004 \\
\hline Magnaporthe oryzae & Foliar & Hemibiotroph (short biotrophic stage) & Parker et al. 2008 \\
\hline Ramularia collo-cygni & Foliar & Hemibiotroph (long asymptomatic stage) & Stabentheiner et al. 2009 \\
\hline Oculimacula acuformis & Stem base & Necrotroph & Blein et al. 2009 \\
\hline Oculimacula yallundae & Stem base & Hemibiotroph (short biotrophic stage) & Blein et al. 2009 \\
\hline
\end{tabular}


nis f. spp. hordei, avenae, and tritici from barley, oat, and wheat, respectively, are incompatible with Brachypodium distachyon, leading to hypersensitive cell death (Draper et al. 2001).

The current study was undertaken to i) investigate the effect of disruption of BR perception on disease resistance to a range of cereal fungal pathogens and ii) determine whether the effect of BRII mutation on disease resistance is conserved between barley and B. distachyon.

\section{RESULTS}

\section{Mutation of $B d B R I 1$ and $H v B R I 1$ enhances resistance \\ to $M$. oryzae.}

Wheat-adapted isolates of $M$. oryzae, which also infect barley, were used to investigate the impact of BRII mutation on disease resistance. Following inoculation, BdBRII developed numerous necrotic lesions characteristic of a compatible $M$. oryzae interaction by 4 days postinoculation (dpi). In contrast, lesions on Bdbril plants were both smaller and less numerous. Disease continued to develop and, by $10 \mathrm{dpi}$, the average percentage of necrotic area on BdBRII leaves was significantly greater $(P<0.001)$ than that on Bdbril leaves (Fig. 1A, C, and D). Following spray inoculation of barley with $M$. oryzae, lesions developed rapidly on both 'Bowman' and 'Akashinriki', with disease being more severe on the former. Both Hvbril semidwarf lines were more resistant to blast infection than their respective $H v B R I 1$ lines, with leaves of the Hvbril genotypes having significantly fewer necrosis-ringed lesions than those of HvBRII $(P<0.001$ and $P=0.015$ in the Bowman and Akashinriki pairs, respectively) (Fig. $1 \mathrm{~B}$ and $\mathrm{E}$ to $\mathrm{H}$ ).

A
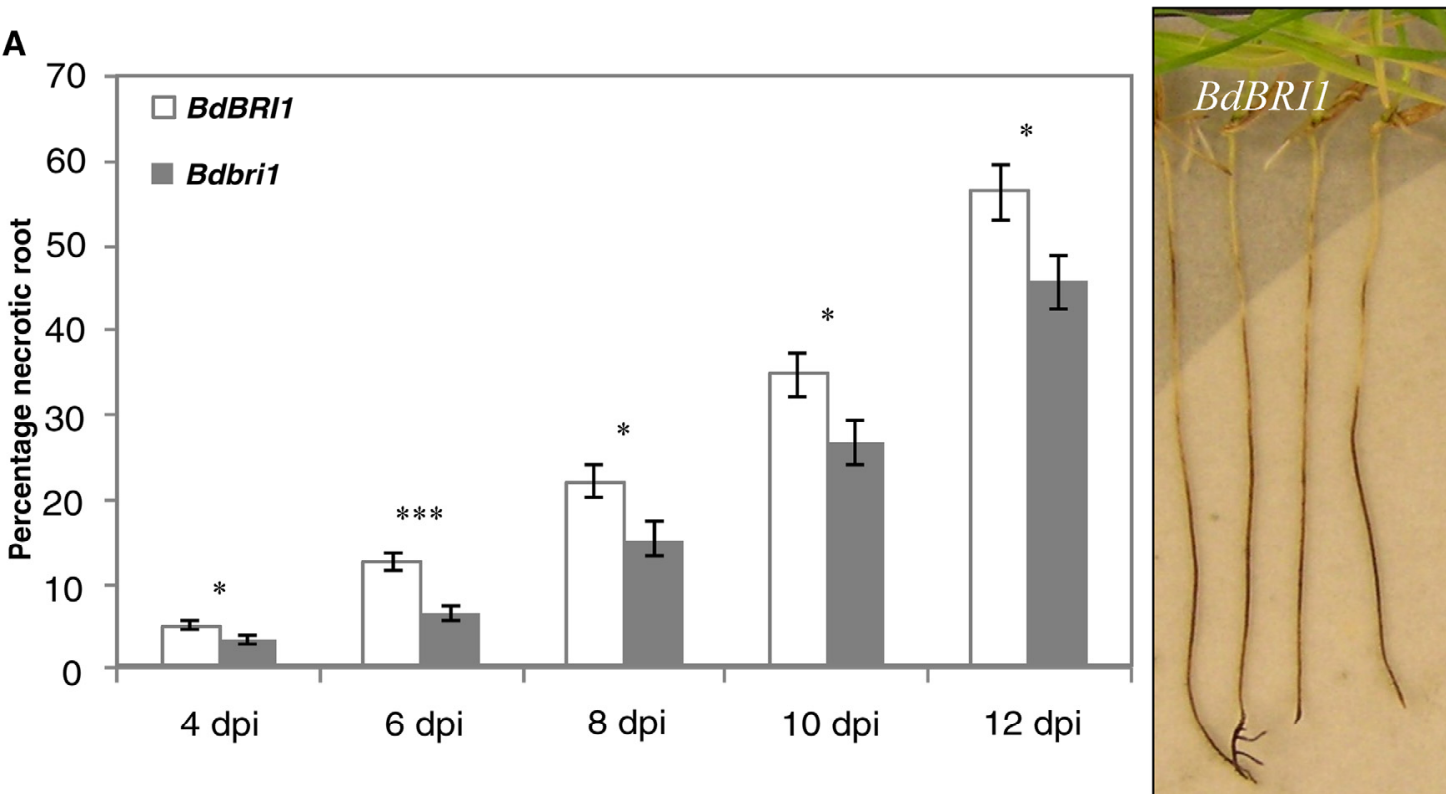

B

C
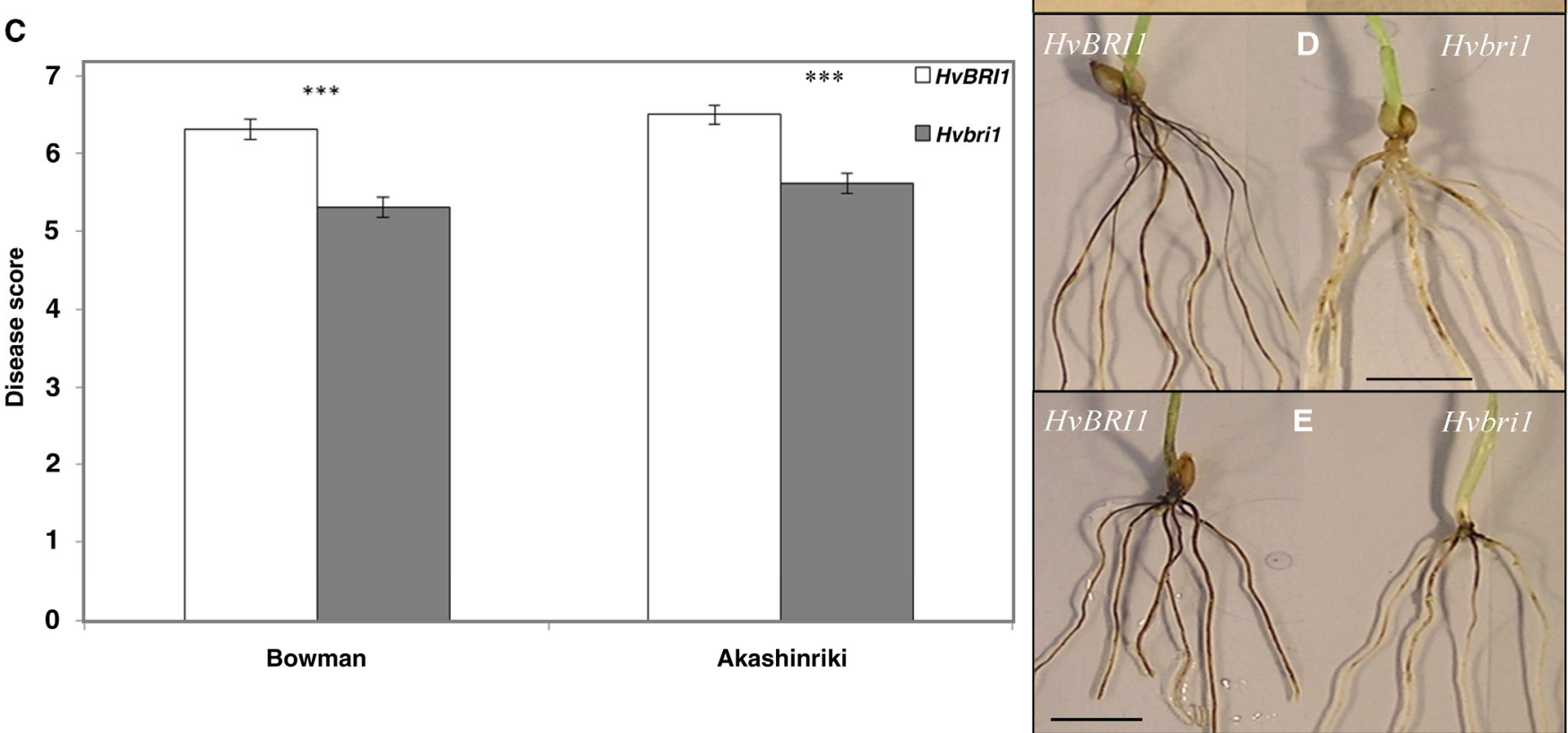

Fig. 2. Take-all symptoms on Brachypodium distachyon and barley roots. A, Percentage of necrotic BdBRII and Bdbri1 roots 4 , 6 , 8 , 10 , and 12 days postinfection (dpi) with Gaeumannomyces graminis. Error bars indicate standard errors of data from 24 observations. B, Images of take-all root infection tests on BdBRII (left) and Bdbril (right) roots, 12 days following G. graminis infection. C, Visual disease score on HvBRII and Hvbril roots in both Bowman and Akashinriki genetic background, 21 days following $G$. graminis infection. Error bars indicate standard errors of data from 25 observations. D, Bowman HvBRI1 (left) and Hvbril (right) and E, Akashinriki HvBRI1 (left) and Hvbril (right) seedlings, 21 days following G. graminis infection. *** and * indicate $P$ value $<0.001$ and 0.05 , respectively. $P$ values were obtained by Student's $t$ test analysis. Scale bars $=1 \mathrm{~cm}$. 


\section{Mutation of $B d B R I 1$ and $H v B R I 1$ enhances resistance to G. graminis var. tritici.}

Progression of take-all disease was significantly slower on roots of Bdbril seedlings compared with $B d B R I 1$ roots at all time-points $(4,6,8,10$, and $12 \mathrm{dpi} ; P=0.03$ and $<0.001$, $0.023,0.038$, and 0.024, respectively) (Fig. 2A and B). Similar results were obtained following inoculation of the barley Bowman and Akashinriki pairs. HvBRIl lines were significantly more susceptible $(P<0.001)$ to $G$. graminis infection than Hvbril lines, exhibiting a greater number of blackened roots with much more severe symptoms (Fig. 2C to E).

\section{Mutation of $B d B R I 1$ and $H v B R I I$}

does not influence resistance to $R$. collo-cygni.

Following infection of $B$. distachyon with $R$. collo-cygni, necrotic and chlorotic areas on leaves were assessed separately 16 days following spray inoculation (Makepeace et al. 2008). No significant difference was observed in the percentage of necrotic $(P=0.762)$ or chlorotic $(P=0.867)$ leaf area between $B d B R I 1$ and Bdbril leaves (Fig. 3A). Similar results were observed for susceptibility of the Bowman and Akashinriki barley Hvbril lines to $R$. collo-cygni. No significant difference in percentage maximum area under disease progress curve (AUDPC) score was observed between lines possessing the Hvbril mutation $(P=0.175$ and 0.278 in Bowman and Akashinriki pairs, respectively) and those possessing the $H v B R I I$ gene in any of three independent experiments (Fig. 3B).
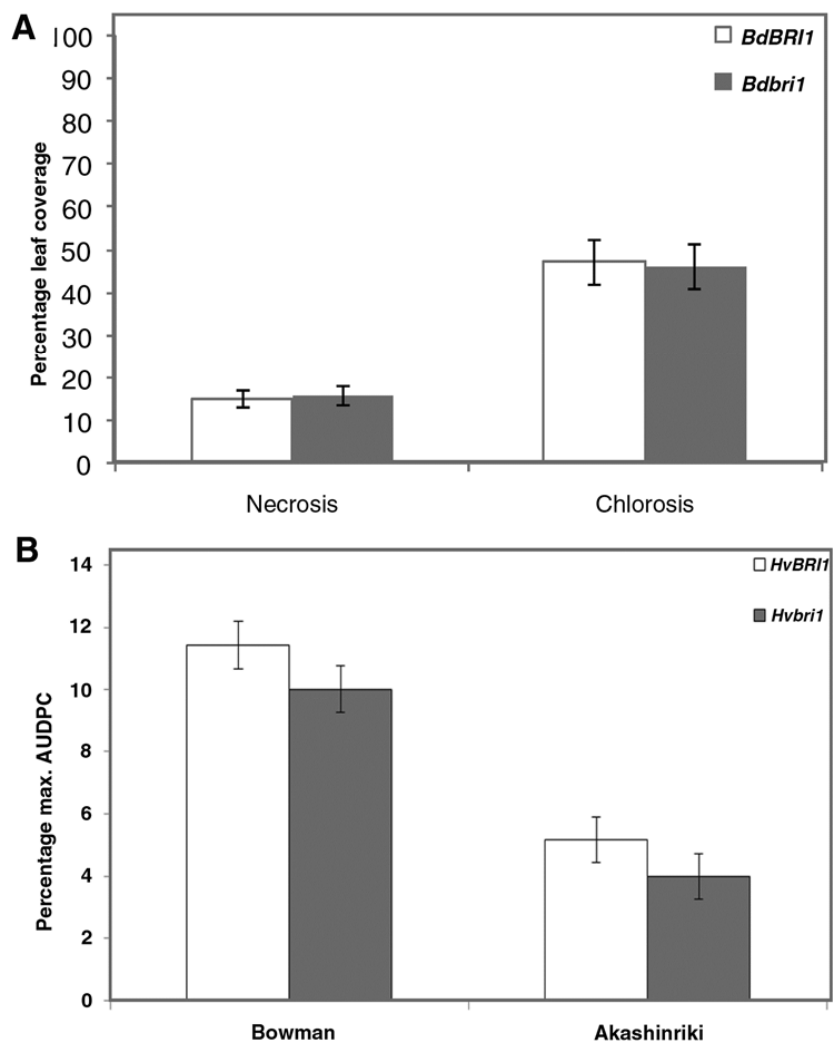

Fig. 3. Ramularia leaf spot symptoms on Brachypodium distachyon and barley leaves. A, Visual disease assessment of necrotic and chlorotic components of Ramularia leaf spot symptoms developed on BdBRII and Bdbril leaves 16 days following spray inoculation with Ramularia collocygni. Error bars indicate standard errors of data from 40 observations. B, Percentage maximum area under disease progress curve of Ramularia leaf spot symptoms developed on leaves of HvBRI1and Hvbril plants, in both the Bowman and Akashinriki genetic background, 28 days postinoculation. Error bars indicate standard errors of data from 30 observations. $P$ values were obtained by Student's $t$ test analysis.
Mutation of $B d B R I 1$ and $H v B R I 1$ enhances resistance to $F$. culmorum in most tissues.

$B d B R I 1$ and Bdbril plants were assessed in their resistance to FHB by monitoring symptom development on inoculated spikelets. Bdbril plants were severely dwarfed and had contorted foliar, floral, and stem tissues (Thole et al. 2012). To address this, all disease assessment data were normalized over the average tissue length or area. At the time of the first disease assessment ( $5 \mathrm{dpi}$ ), disease symptom severity was similar $(P=0.347)$ in spikelets of the BdBRII and Bdbril lines (Fig. $4 \mathrm{~A}$ to $\mathrm{C}$ ). However, necrotic lesions developed more rapidly on BdBRII spikelets than on spikelets of Bdbril plants and symptoms were significantly more severe on spikelets of the $B d B R I 1$ line than on those of the Bdbril line by 10 and $15 \mathrm{dpi}$ $(P=0.003$ and 0.002 , respectively). To further characterize the impact of BRII mutation on the resistance to Fusarium sp. infection, BdBRII and Bdbril seedlings were assessed in their response to FRR by monitoring the progression of necrotic symptoms on inoculated roots. Although Bdbril roots have normal morphology, we observed that they have a slightly reduced growth rate (approximately $85 \%$ of $B d B R I 1$; results not shown); therefore, disease was assessed as a percentage of the root length exhibiting necrotic symptoms. The disease symptoms on BdBRII and Bdbril roots were significantly different at all time-points $(P<0.001$ at 4 and 6 dpi and $P=$ 0.007 at $10 \mathrm{dpi}$ ), with a lower proportion of necrotic lesions on the Bdbril roots compared with those of BdBRII (Fig. 4I to L). Barley Hvbril and HvBRII lines were assessed in their response to both FHB and FCR. Susceptibility to FHB in barley was assessed through spray inoculation of field plots in two successive years (2012 and 2013) followed by visual disease scoring. No significant difference in the combined disease scores between semidwarf Hvbril and HvBRII lines $(P=0.457$ and 0.197 in Bowman and Akashinriki pairs, respectively) was visible (Fig. 4D to $H$ ). Susceptibility to FCR was determined by the ability of the pathogen to penetrate through successive leaf sheaths at the stem base following stem base infection. The HvBRII lines of both Bowman and Akashinriki were significantly more susceptible $(P<0.001)$ to FCR than those possessing the Hvbril mutation, with more leaf sheaths showing the brown discoloration characteristic of the disease (Fig. 4M to O). In an additional set of experiments, seedlings were wounded at the stem base to encourage infection prior to inoculation (Knight and Sutherland 2013). With this procedure, the differential susceptibility was lost and no significant difference in FCR symptoms were seen between $H v B R I 1$ and Hvbril $(P=$ 0.103 and 0.064 in Bowman and Akashinriki pairs, respectively) (Supplementary Fig. S2A to C). Although F. culmorum can infect stem tissues of $B$. distachyon (Peraldi et al. 2011), the nature of the stem base of $B$. distachyon makes study of infection of this tissue particularly problematic in the dwarfed $B d b r i l$ line, and no attempt was made to examine crown rot of B. distachyon in the current work.

\section{Mutation of $\mathrm{HvBRII}$ enhances resistance to Oculimacula spp.}

In experiments with Oculimacula spp., B. distachyon plants were grown at 10 and $16^{\circ} \mathrm{C}$ in two separate experiments. Prior to infection with Oculimacula spp., Bdbril plants displayed a severe browning phenotype which did not occur in BdBRII plants. However, the severe impact cold stress had on Bdbril plants was judged to be a hindrance for the visual assessment of eyespot symptoms at the stem base (Fig. 5B and C). Therefore, data on the resistance to eyespot could not be collected. The semidwarf Hvbril lines were significantly more resistant to infection by $O$. yallundae species than $H v B R I I$ lines $(P<$ $0.001)$, with the fungus penetrating through fewer successive 

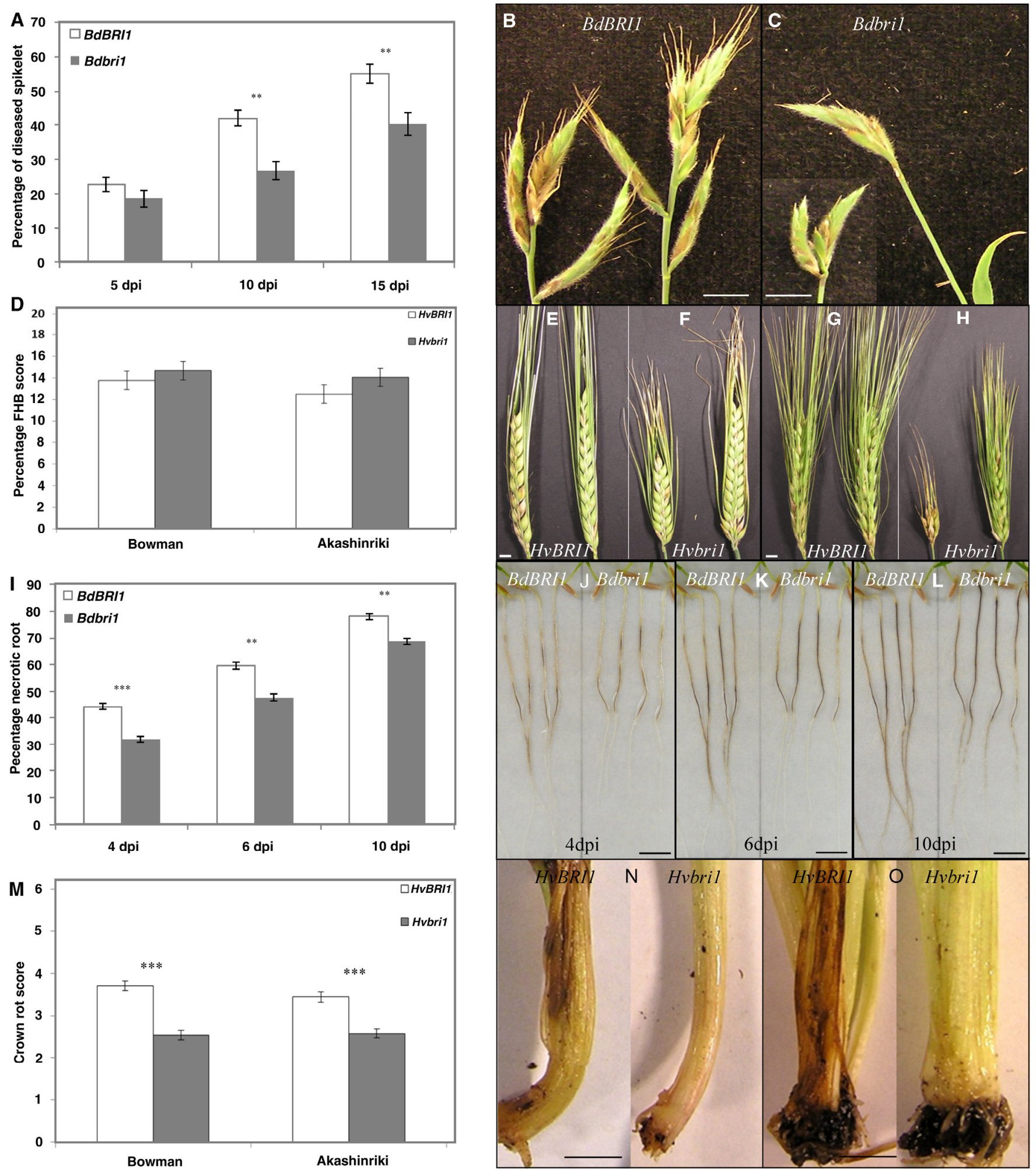

Fig. 4. Fusarium culmorum infection tests on Brachypodium distachyon and barley lines. A, Visual disease assessment of F. culmorum infection on BdBRII and $B d b r i 1$ flowers, 5, 10, and 15 days postinoculation (dpi). Error bars indicate standard errors of data from 57 to 64 observations. Images of $\mathbf{B}, B d B R I 1$ and C, Bdbril flowers, 10 days following F. culmorum sprayed infection. D, Percentage of HvBRII and Hvbril flowers infected with F. culmorum in the field, in both Bowman and Akashinriki background, 21 dpi. Error bars indicate standard errors of data from 13 observations over two experiments. Images of Fusarium head blight symptoms on barley heads spray inoculated with F. culmorum conidia (21 dpi) from the 2012 field trial: E, Bowman HvBRII; F, Bowman Hvbril; G, Akashinriki BdBRI1; and $\mathbf{H}$, Akashinriki Bdbril. Heads on the left of each pair represent heads subjected to drought stress, while those on the right represent nonstressed heads. I, Percentage of necrotic BdBRII and Bdbri1 roots 4, 6, and 10 days following F. culmorum infection. Error bars indicate standard errors of data from 24 observations. Images of BdBRII (left) and Bdbril (right) roots $\mathbf{J}, 4 ; \mathbf{K}, 6$; and $\mathbf{L}, 10$ days following $F$. culmorum infection. M, Visual crown rot scores of HvBRII and Hvbril seedlings, 21 days following nonwounded stem-base infection with F. culmorum. Error bars indicate standard errors of data from 25 observations. Images of nonwounded stem bases of N, Bowman HvBRII (left) and Hvbril (right) and $\mathbf{O}$, Akashinriki HvBRII (left) and Hvbril (right) stem bases 10 days following F. culmorum infection. ** and *** indicate $P$ value $<0.01$ and 0.001 , respectively. $P$ values were obtained by Student's $t$ test analysis. Scale bars $=1 \mathrm{~cm}$. 
leaf sheaths. Similar results were obtained following stem base infection with $O$. acuformis. The Hvbril lines were more resistant than the Bowman and Akashinriki $H v B R I 1$ lines but the differential was less pronounced $(P=0.004$ and 0.002 in Bowman and Akashinriki pairs, respectively) (Fig. 5A, D, and E).

\section{Mutation of $H v B R I 1$ does not alter resistance to Blumeria graminis f. sp. hordei.}

Studies with Blumeria graminis f. spp. hordei, avenae, and tritici have shown that these formae speciales are incompatible with $B$. distachyon, leading to hypersensitive cell death (Draper et al. 2001) (Fig. 6D). Therefore, the role of BRII in resistance to $B$. graminis f. sp. horde $i$ was only investigated in barley, as an example of an interaction with a biotrophic pathogen. The two-row Bowman was more susceptible to the $B$. graminis f. sp. hordei isolates used in the current study than the six-row Akashinriki (Fig. 6A). However, no significant difference in susceptibility to $B$. graminis f. sp. hordei was observed in detached leaf assays between the $H v B R I 1$ and semidwarf Hvbril lines for either of the barley pairs $(P=0.374$ and 0.183 in Bowman and Akashinriki pairs, respectively) (Fig. 6A to C).

\section{DISCUSSION}

BR along with a second phytohormone, GA, have important roles in plant growth and development. Attenuating GA signaling through mutation of DELLA proteins was very important in agriculture, with the reduced height (Rht) semidwarfing alleles in wheat being central to advances in crop yield that occurred during the so-called "Green Revolution" (Achard et al. 2006; Navarro et al. 2008; Peng et al. 1999). However, such mutations have pleiotropic effects on disease resistance, leading to increased resistance to necrotrophic and hemibiotrophic fungi but increased susceptibility to biotrophic pathogens and those with a long latent period of infection (Saville et al. 2012). The availability of mutant lines in the main BR receptor $(B R I 1-u z u)$ in barley provides an opportunity to determine whether disruption or attenuation of the BR signaling pathway also affects disease resistance and whether the effect is similar to that observed for GA.

Brachypodium distachyon has often been proposed as an ideal species with which to undertake studies aimed at modelto-crop translation. B. distachyon can form compatible interactions with a wide range of fungal pathogens that cause economically important diseases of small-grain cereals such as wheat and barley, making $B$. distachyon a potential model for investigating resistance to these diseases. To date, however, there has been very little evidence to demonstrate conservation of function between $B$. distachyon and cereals with respect to disease resistance. The availability of mutations in BRII in both barley and $B$. distachyon provided an opportunity to investigate whether interference in BR perception or signaling has similar effects on disease resistance in both the $B$. distachyon model and barley crop species.
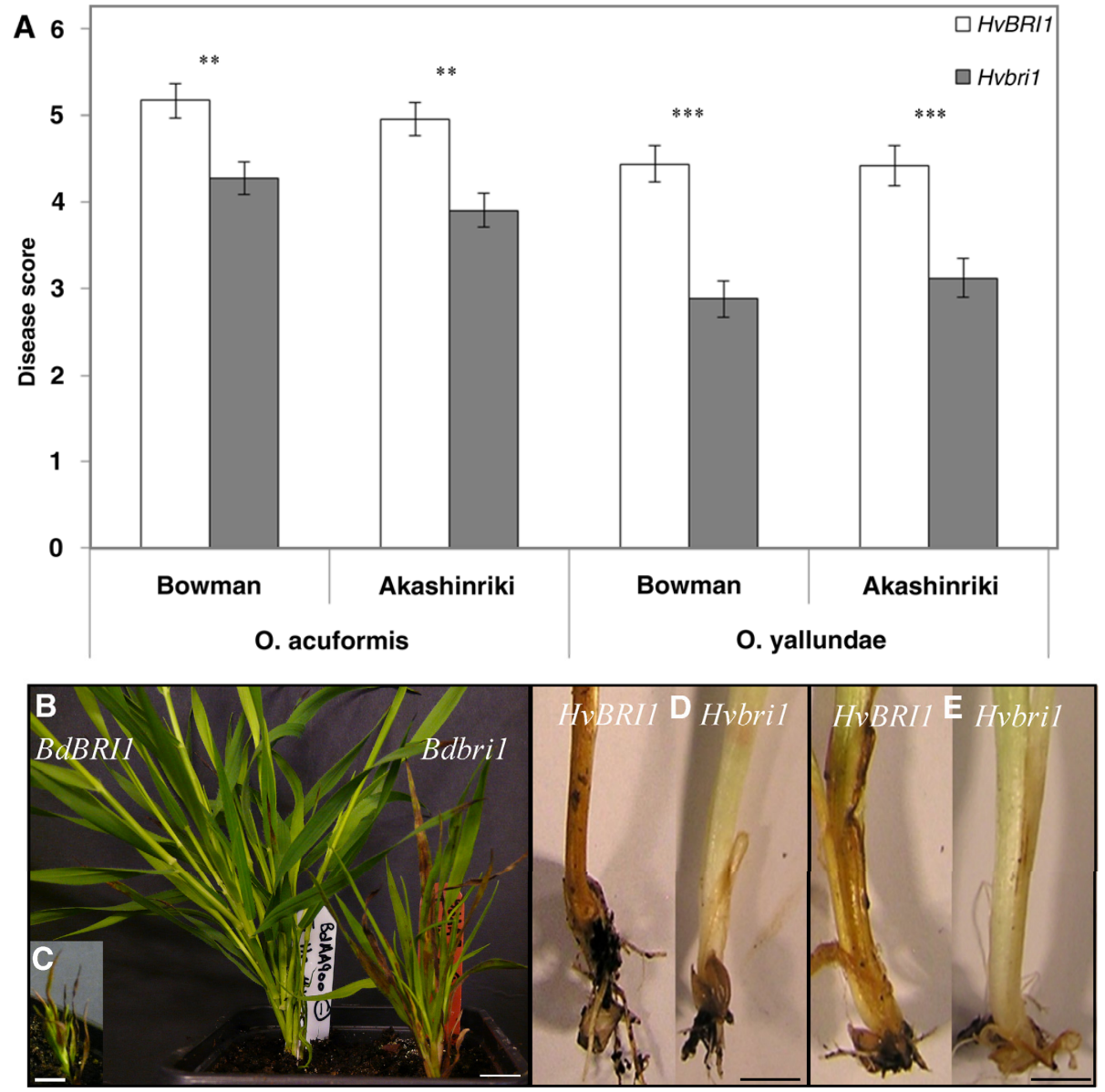

Fig. 5. Eyespot symptoms on barley plants. A, Visual disease scores of HvBRI1 and Hvbril plants, 56 days following stem infection with either Oculimacula acuformis or $O$. yallundae, in both the Bowman and Akashinriki genetic background. Error bars indicate standard errors of data from 25 observations. B and C, BdBRI1 (left) and Bdbril (right) plants (8 weeks old) grown at $16^{\circ} \mathrm{C}$. B, Bdbril leaves displayed purple-brown lesions similar to anthocyanin- or phenolic-like compound accumulation. $\mathbf{C}$, Image of extreme case of dwarfism displayed by $B d b r i 1$ plants grown at $16^{\circ} \mathrm{C}$. Images of $\mathbf{D}$, Bowman $H v B R I 1$ (left) and Bdbril (right) and E, Akashinriki HvBRI1 (left) and Hvbril (right) stem bases, 56 days after $O$. yallundae infection. *** and ** indicate $P$ value $<0.001$ and 0.01 , respectively. $P$ values were obtained by Student's $t$ test analysis. Scale bars $=1 \mathrm{~cm}$. 


\section{Role of BR signaling in resistance} to pathogens with differing trophic lifestyles.

Disruption of BRII led to an increase in disease resistance to necrotrophic pathogens and hemibiotrophs with a very short biotrophic phase ( $G$. graminis var. tritici and $M$. oryzae) in both $B$. distachyon and barley on both leaves ( $M$. oryzae) and root tissues ( $G$. graminis var. tritici). In contrast, disruption of $B R I 1$ had no discernable effect on resistance toward Blumeria graminis var. hordei and $R$. collo-cygni in barley. B. graminis is an obligate biotroph (Both et al. 2005), while $R$. collo-cygni is a hemibiotroph with a prolonged asymptomatic endophytic phase (Stabentheiner et al. 2009).

Interestingly, the effect of BRII mutation on infection by $F$. culmorum appeared to differ with tissue. This probably reflects differences in the mode of infection. During infection of floral tissues of wheat, F. culmorum initially grows intercellularly with little or no disruption of the host tissues before adopting a necrotrophic growth style (Brown et al. 2010). No such initial biotrophic stage has been observed during the infection and colonization of stem base or root tissues (Beccari et al. 2011; Chen et al. 2013). This difference in trophic styles during infection of floral and stem-base or root tissues may explain the observed difference in the effect of BRII mutation in these tissues. The effect of the $H v B R I 1$ mutation on stem-base infection was dependent upon the inoculation method. When unwounded, the Hvbril lines were significantly more resistant to F. culmorum than their wild-type near-isogenic lines (NIL). However, this difference was lost when the stems were wounded immediately prior to inoculation.

Physical trauma of plant tissues such as wounding or herbivore feeding activates a signaling cascade that leads to the pro- duction of different mobile signals, the predominant of which are ET and JA (León et al. 2001; O'Donnell et al. 1996). In Arabidopsis, Makandar and co-workers (2010) reported that mutation of some of the core signaling components of the JA pathway (opr3, coil, and jarl) increased resistance of Arabidopsis plants challenged with $F$. graminearum, a very close relative of $F$. culmorum. The observation of increased induction of pathogenesis-related 1 transcripts and SA accumulation in opr3 and jarl mutants compared with the wild-type plants led the authors to conclude that the JA-induced susceptibility may function via attenuation of SA-induced defense mechanisms. Antagonism between the JA/ET and SA signaling pathway is well documented (Robert-Seilaniantz et al. 2011). Similarly, ET signaling was shown to be a factor of susceptibility to infection by Fusarium spp. in Arabidopsis, wheat, and barley (Chen et al. 2009). Therefore, it is reasonable to assume that wounding of barley stem bases activates JA and ET signaling pathways, both of which have been shown to increase susceptibility to Fusarium spp. It is possible that signaling resulting from the wounding pretreatment may swamp the effect of the BRI1-related differential response observed between the $H v B R I 1$ and Hvbril lines in the absence of wounding.

An emerging body of evidence suggests that BR are involved in the regulation of plant defense responses (Bari and Jones 2009). For instance, Belkhadir and colleagues (2012) reported that BR function in an antagonistic manner to PTI that is triggered by PAMPs such as chitin and flagellin. Studies conducted in Arabidopsis showed that activation of the BRII pathway inhibits the PTI signaling mediated by several pattern-recognition receptors (Albrecht et al. 2012). Mutation of BRII would be anticipated to alleviate this antagonism and, perhaps, lead
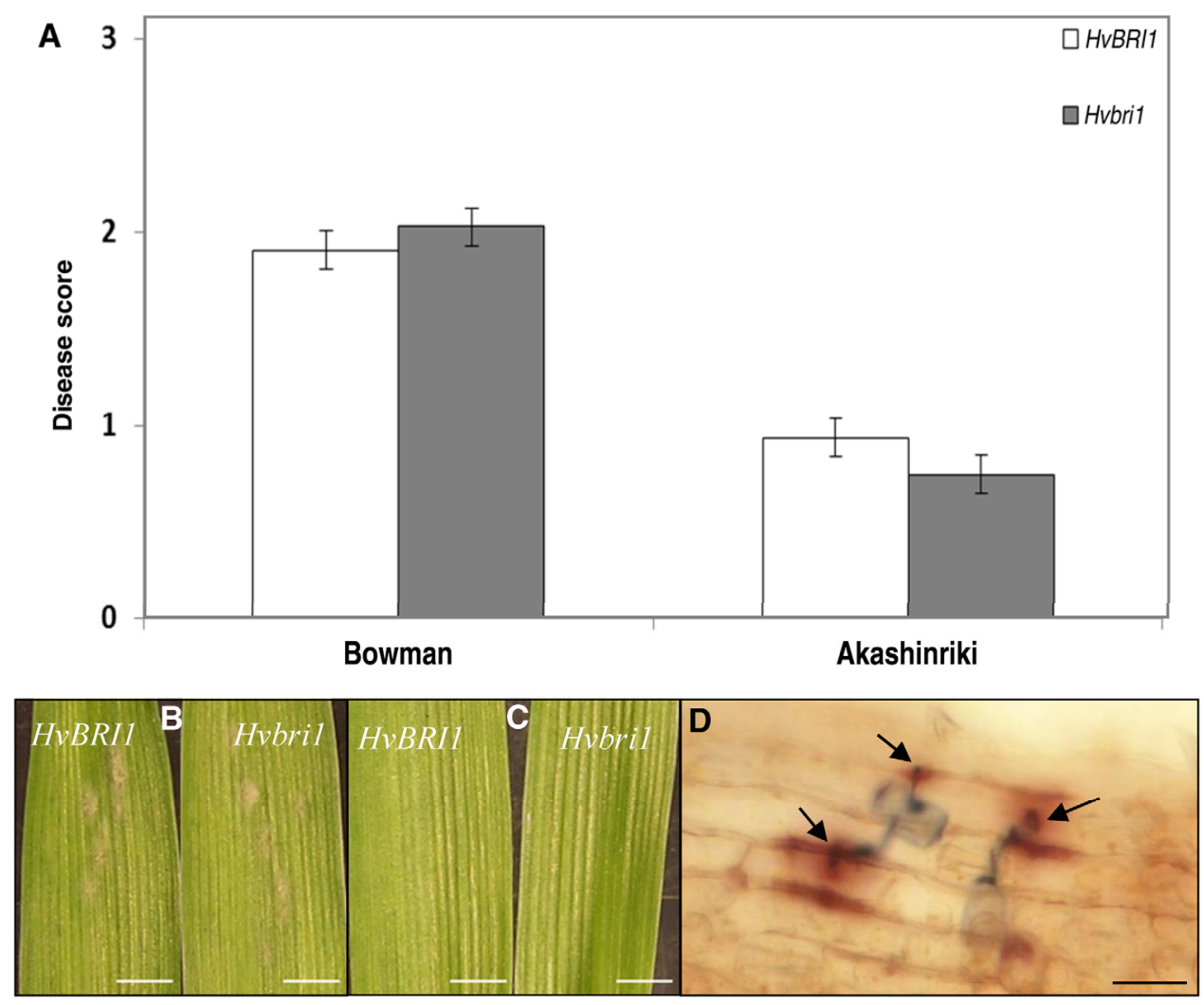

Fig. 6. Powdery mildew infection tests on barley. A, Visual disease scores of Blumeria graminis f. sp. hordei infection on HvBRI1 and Hvbril leaves, in both the Bowman and Akashinriki genetic background, 10 days following spray inoculation. Error bars indicate standard errors of data from 24 to 36 observations over three experiments. Images of powdery mildew symptoms developed on B, Bowman $H v B R I 1$ (left) and $H v b r i l$ (right) and $\mathbf{C}$, Akashinriki HvBRI1 (left) and Hvbril (right) 10 days following B. graminis f. sp. hordei infection. Scale bars $=1 \mathrm{~cm}$. D, Composite microscope image of $0.01 \%$ aniline-blue-stained $B$. graminis f. sp. hordei spores on the surface of Bd21 leaves, 10 days following infection. $P$ value $<0.05$. $P$ values were obtained by Student's $t$ test analysis. Arrows indicate papillae. Scale bar $=20 \mu \mathrm{m}$. 
to enhanced efficiency of PTI. Our data would support the view that $B R$ signaling functions antagonistically with basal defense mechanisms because BRII mutation enhanced resistance against a broad range of pathogenic microorganisms despite differences in their infection and virulence strategies. This antagonistic situation also supports the hypothesis that some pathogens may have evolved mechanisms to exploit BR/PTI antagonism. This was the conclusion of De Vleesschauwer and colleagues (2013) who, based on their results, developed a model whereby $P$. graminicola hijacks the plant BR-signaling pathway as a decoy to antagonize otherwise effective SA- and GA-mediated defense mechanisms. Currently, nothing is known about the molecular components controlling the antagonistic relationship between growth and immunity in monocotyledons. However, recent work in Arabidopsis from two independent groups demonstrated that the basic helix-loop-helix transcription factor HBI1 negatively regulates genes involved in the onset of PTI while positively regulating BR-triggered responses (Fan et al. 2014; Malinovsky et al. 2014). It would be of prime interest to test whether HBI1 orthologs are conserved in monocot plant species and whether these also control an antagonistic cross-talk mechanism between growth and immunity.

In contrast to the effects of BR on PTI, other studies have proposed that BR have a positive role in resistance. For example, exogenous application of BR was shown to increase resistance to M. grisea and Xanthomonas oryzae pv. oryzae in rice and resistance to Tobacco mosaic virus, Pseudomonas syringae pv. tabaci, and Oidium spp. in tobacco (Nakashita et al. 2003). This report appears difficult to reconcile with our findings that BRII mutation reduced disease caused by M. oryzae in both Brachypodium distachyon and barley. Similarly, Ali and colleagues (2013) reported the first study implicating BR in resistance to Fusarium spp. in barley. The authors observed that exogenous application of epibrassinolide, whether applied to flowers or added in the soil, enhanced resistance to FHB and seedling blight, respectively, caused by $F$. culmorum in barley plants. This appears contradictory to our findings that mutation of BRII enhances resistance in both B. distachyon and barley plants. However, a recent report taking a genetic rather than chemical approach supports the findings from the present work that disruption of BRII in barley leads to enhanced resistance to crown rot. Chen and colleagues (2014) demonstrated that barley $u z u$ (Hvbril) lines are more resistant to FCR than their tall equivalents, indicating that reduced BR signaling enhances resistance to Fusarium spp.

Interestingly, both the studies of Ali and associates (2013) and Nakashita and associates (2003) employed a chemical approach to investigate the effect of BR on disease resistance. Therefore, their findings reflect the effect of exogenous application of phytohormones to plants whose cellular signaling machinery is intact and fully responsive to the hormone. In the current study and that of Chen and associates (2014), a genetic approach was employed to investigate the impact of BR signaling on disease resistance. The barley Hvbril and Bdbril lines investigated here are hypo- or insensitive to the BR signal. Plants carrying genetic mutations that impair or prevent activation of a particular phytohormone pathway will compensate for such a defect via differential regulation of other hormonal signaling pathways. Hence, findings from genetic studies may not correspond directly to those from studies using chemical approaches because the former examines the effect of constitutive disruption of a pathway whereas the latter generally examines the effect of supplementing or overloading a pathway. In addition, responses to phytohormone application are frequently dependent upon concentration. For example, Clouse and colleagues (1996) reported that root growth of
Arabidopsis seedlings was reduced when exposed to high concentrations of brassinolide but stimulated at low concentrations. Similarly, Zhao and colleagues (2004) reported that production of the phytoalexin $\beta$-thujaplicin was stimulated by moderate ET concentrations, whereas excessive concentrations of ET reduced $\beta$-thujaplicin levels to below those in untreated plants.

\section{Correspondence between the effects}

\section{of disrupted BR perception in B. distachyon and barley.}

In all instances where direct comparison could be made between the effect of BRII mutation on disease resistance in $B$. distachyon and barley, the effect was similar in both hosts. For example, BRII mutation enhanced resistance to foliar infection by $M$. oryzae and to root infection by $G$. graminis var. tritici in both species. Conversely, mutation of BRII had no influence on disease symptoms in either $B$. distachyon or barley following infection by $R$. collo-cygni. These results show a strong correspondence of the effect induced by BRII mutation on disease resistance because the trend in alteration of resistance observed in $B$. distachyon was confirmed in barley. However, in one instance, the relationships appeared to be more complex.

Following spray inoculation of heads of $B$. distachyon with $F$. culmorum, there was no difference in disease symptoms between the Bdbril and the BdBRII line at 5 dpi. Thereafter, disease developed more rapidly on $B d B R I 1$ than on the Bdbril line as additional spikelets became infected due to the fungus spreading within adjacent tissues. Two types of FHB resistance are widely recognized (Schroeder and Christensen 1963). Type 1 describes the resistance of the spike to initial fungal penetration and type 2 describes resistance to spread through the rachis from infected to noninfected spikelets. Most wheat varieties have little or no type 2 resistance. In contrast, barley varieties have inherently high levels of type 2 resistance and differences in FHB susceptibility are due to different degrees of type 1 resistance (Bai and Shaner 2004). We previously showed that $B$. distachyon mirrors more closely the situation in wheat, because the fungus is able to move through head tissues to infect adjacent spikelets (Peraldi et al. 2011). The data from $B$. distachyon floral infection indicate that disruption of BRII had no effect on resistance to initial infection (type 1 resistance) but did lead to an increase in type 2 resistance. Data from the two replicated field experiments involving the barley $\mathrm{HvBRII}$ lines provided no evidence for a role of $B R I 1$ in FHB resistance of barley. Because FHB symptoms do not spread in barley, it is concluded that this also reflects a lack of effect of BRII mutation on type 1 resistance. Therefore, this concurs with the situation in B. distachyon, where disruption of BRII had no effect on type 1 resistance. Together, these results support the view that BRII mutation affects mechanisms associated with type 2 resistance to $\mathrm{FHB}$, the element where the fungus adopts a necrotrophic mode of colonization.

Interestingly, Bdbril flower structure is more compact and has a reduced average number of spikelets, each spikelet bearing fewer florets compared with BdBRII. These structural alterations were expected to increase the microclimate relative humidity and reduce the surface area necessary to achieve complete colonization of the spikelet by the fungus. It was anticipated that such alterations would favor fungal progression because high humidity is known to be conducive for the development of FHB in cereals (Xu et al. 2007). Therefore, it seems that the reduction in symptom progression observed on Bdbril spikelets is a genetic effect rather than a consequence of morphological alteration.

Overall, the results from host-pathogen interaction studies strongly indicate that BR signaling plays a similar role in resistance to a broad range of pathogens infecting different 
host tissues in both $B$. distachyon and barley. Such results lend support to the view that $B$. distachyon is a suitable host species model with which to model interactions with economically important pathogens of cereals.

\section{Differential effects of GA and BR dwarfing genes on stress-response trade-offs.}

A trade-off in resistance to pathogens with differing trophic lifestyles has been observed following disruption of GA signaling (Saville et al. 2012). GA acts to promote cell elongation and growth (Sun and Gubler 2004) and is negatively regulated by DELLA growth-repressor proteins, which are degraded in the presence of GA (Achard and Genschik 2009). Wheat $R h t$ and barley slenderl $(S \ln 1)$ gain-of-function alleles encode mutant forms of DELLA proteins and are insensitive to gibberellin (Chandler et al. 2002; Peng et al.1999), preventing degradation of these proteins, causing inhibition of stem elongation, and conveying a dwarf phenotype. The Rht and $\operatorname{Sin} 1$ dwarfing alleles have pleiotropic effects on immunity. In response to biotrophic fungi, the barley $\operatorname{Sin} 1 d$ line is more susceptible than the wild-type tall line, yet $\operatorname{Sin} 1 d$ is more resistant to disease caused by necrotrophic fungi (Saville et al. 2012). Rht or Sln gain-of-function mutation also leads to greater tolerance of abiotic stresses such as high salinity (Achard et al. 2006) due to increased reactive oxygen species scavenging through activity of NADPH oxidases (Achard et al. 2008).

BR are growth-promoting hormones that, like GA, are associated with cell elongation (Szekeres et al. 1996). Mutation of BRII results in dwarfism in both dicot and monocot species (Chono et al. 2003; Clouse et al. 1996; Thole et al. 2012; Yamamuro et al. 2000). We have shown that mutation of BRII also has pleiotropic effects on disease resistance. Reduced BR sensitivity leads to increased resistance to necrotrophic and hemibiotrophic fungal pathogens with a very short biotrophic phase. However, unlike the Rht and $\operatorname{Sin} 1$ GA-insensitive alleles, BRI1 mutation in barley does not suffer a disease resistance trade-off conferred through increased susceptibility to biotrophic pathogens. The absence of the biotroph-necrotroph disease trade-off following impairment of BR signaling suggests that manipulation of this pathway may have potential agricultural use in breeding varieties with reduced height without compromising resistance to biotrophic pathogens.

Although the absence of a biotroph-necrotroph trade-off in both $B$. distachyon and barley bril lines suggests that such a mutation may be advantageous in plant breeding, disruption of the BR signaling pathway has been linked to reduced tolerance to abiotic stress. Koh and associates (2007) observed that TDNA knockout of $O s G S K 1$, the rice ortholog of BIN2 and a negative regulator of $\mathrm{BR}$ signaling in Arabidopsis, which induces hypersensitivity to BR application, increased tolerance to abiotic stresses such as cold and drought. Interestingly, cultivation of $u z u$ barley lines is restricted to regions where plants are less likely to be exposed to low temperatures or other stresses (Saisho et al. 2004). In this study, exposure to prolonged low temperature led to severe stress-related symptoms in Bdbril plants (Fig. 5B and C). It would be extremely valuable to further characterize the effect of BRII mutation on coldand drought-stress tolerance in order to confirm the potential use of mutation of this target as an alternative to $R h t$ alleles in commercial cereal varieties.

\section{MATERIALS AND METHODS}

\section{Plant material and growth conditions.}

The $B$. distachyon homozygous mutant (Bdbril) and null segregant control line $(B d B R I 1$, derived from the original T0 plant but carrying the nontransformed [sister] chromosome) were obtained from the BrachyTAG T-DNA mutant collection held at the John Innes Centre (line BdAA900 kindly provided by P. Vain) (Thole et al. 2012). BdBRII and Bdbril plants were grown alongside one another, as detailed by Peraldi and associates (2011). Plants used for flower infection tests were grown under a photoperiod of $20 \mathrm{~h}$ of light and $4 \mathrm{~h}$ of darkness while plants used for seedling spray infection tests were grown under a photoperiod of $16 \mathrm{~h}$ of light and $8 \mathrm{~h}$ of darkness at $22^{\circ} \mathrm{C}$. NIL pairs of barley two-row Bowman $(H v B R I I)$ and Bowman-Uzu (Hvbril) and six-row Akashinriki (HvBRII) and Akashinriki-Uzu (Hvbril) were obtained from the Barley and Wild Plant Resource Center, Okayama University, Japan. In all experiments except for take-all, seed were pregerminated in petri dishes on damp filter paper for $48 \mathrm{~h}$ in the dark at $4^{\circ} \mathrm{C}$ and then incubated at $24^{\circ} \mathrm{C}$ for $24 \mathrm{~h}$, before being transferred to F2 soil (Scotts Professional).

\section{Fungal inoculum.}

M. oryzae wheat-adapted isolate BR32 (provided by G. R. D. McGrann, John Innes Centre, Norwich, U.K.) was maintained at $24^{\circ} \mathrm{C}$, as detailed by Tufan and associates (2009). Wheat-adapted isolate of $G$. graminis T5 (kindly provided by A. Osbourn, John Innes Centre, Norwich, U.K.) was cultured on potato dextrose agar (PDA) under a cycle of $16 \mathrm{~h}$ of light and $8 \mathrm{~h}$ of darkness at $20^{\circ} \mathrm{C}$. R. collo-cygni isolate Rcc09B4 was maintained and inoculum prepared as detailed by Peraldi and associates (2013). A mixture of $O$. acuformis and $O$. yallundae isolates (Chapman et al. 2008) were maintained on V8 agar plates at $16^{\circ} \mathrm{C}$ for 21 days prior to use as inoculum. DONproducing $F$. culmorum isolate Fu42 from the culture collection of the John Innes Centre was maintained and conidial inoculum was prepared as detailed by Peraldi and associates (2011). For barley stem-base infection and B. distachyon root infection tests, $F$. culmorum Fu42 colonies were grown on V8 agar ( $9 \mathrm{~g}$ of bactoagar and $50 \mathrm{ml}$ of V8 vegetable juice in 450 $\mathrm{ml}$ of deionized water) for 14 days at $20^{\circ} \mathrm{C}$. Blumeria graminis f. sp. hordei isolates $\mathrm{CC} 148$ and DH14 from the culture collection of the John Innes Centre were maintained on the barley line Golden Promise, as described by Brown and Wolfe (1990).

\section{Brachypodium seedling spray inoculation.}

Three-week-old Bdbril and BdBRII plants were used for Ramularia and Magnaporthe spray infection tests. Two-weekold liquid cultures of $R$. collo-cygni Rcc09B4 were used to prepare the mycelium fragment suspension and treated as described by Peraldi and associates (2013). In all, 6 to 10 plates of 10- to 14-day-old $M$. oryzae colonies were used to harvest spores in sterile distilled water (SDW) and the conidial concentration was estimated using a hemocytometer. Conidial suspension was diluted to $1 \times 10^{5}$ conidia $/ \mathrm{ml}$ and amended with $0.01 \%$ Tween 20 before plants were sprayed until runoff. Plants were kept under a plastic cover previously misted with SDW to increase relative humidity until disease assessment 4 or 10 dpi for the first and second experimental repeats, respectively.

\section{Brachypodium root inoculation and symptom assessment.}

Seedlings used for root infection were grown for 1 day at $22^{\circ} \mathrm{C}$ under a photoperiod of $16 \mathrm{~h}$ of light and $8 \mathrm{~h}$ of darkness. Bdbril and BdBRII seedlings were transferred onto filter paper (grade 292; Sartorius) placed on the surface of $0.8 \%$ wateragar in $10-\mathrm{cm}^{2}$ clear plastic plates. Plates were placed upright at an approximately $60^{\circ}$ angle for 2 to 3 days in the same conditions to encourage uniform root growth down the plate. Six to eight seedlings of the two lines (Bdbril and BdBRII) were grown on each plate to allow direct comparison between them. For F. culmorum inoculation, 2-week-old Fu42 colonies growing on V8 vegetable juice amended with PDA were homoge- 
nized using a kitchen blender (Braun Multipractic MR30) to obtain a thick slurry. For G. graminis T5 inoculation, 10- to 14-day-old colonies were used to prepare the slurry using the same method as described above, except that SDW was added to obtain a consistency similar to the $F$. culmorum inoculum. Slurry ( 2 to $3 \mathrm{ml}$ ) was deposited onto the roots with a sterile syringe. At 4 dpi, the slurry was delicately washed off. Roots were photographed using a Panasonic DMC-FZ18 digital camera at $4,6,8,10$, and $12 \mathrm{dpi}$ and lesions measured using the ImageJ software (Abramoff et al. 2004).

\section{Brachypodium flower spray inoculation and symptom assessment.}

Plants were sprayed at midanthesis with $F$. culmorum Fu42 conidial suspension $\left(1 \times 10^{5}\right.$ conidia $\left./ \mathrm{ml}\right)$ amended with $0.01 \%$ Tween 20 using a handheld mister as described previously (Peraldi et al. 2011), except that, following inoculation, plants were maintained for 2 days under high relative humidity (approximately $90 \%$ ) before returning to normal growth conditions. Floral symptom development was quantified by visual assessment and the percentage of infected spikelets was determined at 5, 10, and 15 dpi.

\section{Barley seedling spray inoculation.}

Barley seedlings were sown at 10 seeds per 5-by-5-cm pot and grown at 18 and $15^{\circ} \mathrm{C}$ under a photoperiod of $16 \mathrm{~h}$ of light and $8 \mathrm{~h}$ of darkness, respectively. Seedlings were inoculated with $M$. oryzae isolate BR32 as described by Tufan and associates (2009) and incubated under a photoperiod of $16 \mathrm{~h}$ of light and $8 \mathrm{~h}$ of darkness at 24 and $16^{\circ} \mathrm{C}$, respectively, to induce fungal development. At $6 \mathrm{dpi}$, disease symptoms were scored as the number of lesions on the first leaf (Jarosch et al. 2003). Ramularia inoculations with Rcc09B4 were as described by Makepeace and associates (2008). Symptoms were scored from 10 to $28 \mathrm{dpi}$ as a percentage of the first leaf showing RLS lesions. Scores were then calculated as a percentage of the maximum possible AUDPC, assuming a value of $100 \%$ for every score date, to standardize scores across experiments.

\section{Barley root inoculation.}

Inoculum was prepared by homogenizing 14-day-old $G$. graminis T5 culture plates with $\mathrm{H}_{2} \mathrm{O}$ (2:1) and thoroughly mixing with autoclaved $\mathrm{H}_{2} \mathrm{O}$-saturated vermiculite medium (William Sinclair Horticulture Ltd.). Inoculum was added to 50-ml Falcon tubes, with five seeds placed on top of the inoculum and five replicates per genotype. Seedlings were incubated at 18 and $15^{\circ} \mathrm{C}$ under a photoperiod of $16 \mathrm{~h}$ of light and $8 \mathrm{~h}$ of darkness, respectively, for 3 weeks and scored using a numerical system (0-to-10 scale incorporating symptoms in both roots and leaves, with $0=$ no infection and $10=$ whole seedling diseased).

\section{Barley leaf inoculation.}

Detached leaf assays with $B$. graminis f. sp. hordei isolates were performed using the protocol of Boyd and associates (1994). Agar boxes were incubated at 18 and $12^{\circ} \mathrm{C}$ under a photoperiod of $16 \mathrm{~h}$ of light and $8 \mathrm{~h}$ of darkness, respectively, and symptoms were scored at 10 dpi using a 0-to-4 scale (Moseman et al. 1965).

\section{Barley stem base inoculation.}

Barley seedlings for $F$. culmorum stem-base infections were grown at 18 and $15^{\circ} \mathrm{C}$ under a photoperiod of $16 \mathrm{~h}$ of light and $8 \mathrm{~h}$ of darkness, respectively. Seedlings for F. culmorum nonwounded stem-base infection were grown at five seeds per 5-by$5-\mathrm{cm}$ pot, with five replicates per line. Seedlings were inoculated using the method of Simpson and associates (2000), using the following modifications. Inoculum was prepared by homogenizing $\mathrm{Fu} 42$ culture plates with $\mathrm{H}_{2} \mathrm{O}$ (2:1) and seedlings were inoculated with $2 \mathrm{ml}$ of slurry. Seedlings were kept in the dark for $24 \mathrm{~h}$ after inoculation to induce fungal growth and symptoms were scored at $21 \mathrm{dpi}$. F. culmorum-wounded stem base assays followed the protocol of Knight and Sutherland (2013). Wounds were inoculated with $10 \mu \mathrm{l}$ of $1 \times 10^{7}$ conidia per milliliter and incubated in the dark at $25^{\circ} \mathrm{C}$ for $24 \mathrm{~h}$. Seedlings were returned to normal growth conditions and scored at 21 dpi. For Oculimacula stem-base infection, plants were grown and inoculated with either $O$. acuformis or $O$. yallundae using the method of Burt and associates (2010). Plants were incubated at $10^{\circ} \mathrm{C}$ under a photoperiod of $16 \mathrm{~h}$ of light and $8 \mathrm{~h}$ of darkness and harvested 8 weeks post inoculation. Assays were repeated twice with $O$. yallundae isolates and once with O. acuformis. Disease symptoms for all stem-base assays were assessed as the penetration of leaf sheaths by the pathogen, using the system devised by Scott (1971).

\section{Barley field experiment inoculation.}

Seed were sown in $1-\mathrm{m}^{2}$ plots in a randomized complete block design experiment, with five to eight replicates, in the spring of 2012 and 2013 at the John Innes Centre. Plants were spray inoculated from anthesis with an $F$. culmorum $\mathrm{Fu} 42$ conidial suspension of $1 \times 10^{5}$ spores per milliliter $\left(0.5 \times 10^{5}\right.$ spores per milliliter in 2013) and $0.05 \%$ Tween 20, with repeated spraying to ensure even inoculation. Disease was assessed visually 18 to 21 days after the final inoculation as the percentage of symptoms per plot, and data from both experimental years was combined for analysis.

\section{Statistical analysis.}

All experiments were performed at least twice, except for Brachypodium distachyon $R$. collo-cygni infection, which was only performed once. Data from $B$. distachyon experiments was normalized to compensate for the reduction in tissue length or area caused by Bdbril mutation. All disease data scores were analyzed using a generalized linear model (GLM) in the software package GENSTAT (v16.0; Lawes Agricultural Trust, Rothamsted Experimental Station). Within the GLM, paired $t$ tests were used to assess differences in disease symptom severity for each of the B. distachyon and barley BRII/ bril pairs.

\section{ACKNOWLEDGMENTS}

The work was funded by Biotechnology and Biological Sciences Research Council (BBSRC) grant BB/J004553/1 (C. Ridout and P Nicholson) and a BBSRC Industrial CASE award (BrewLab industrial partner) (R. Goddard).

\section{LITERATURE CITED}

Abramoff, M. D., Magelhaes, P. J., and Ram, S. J. 2004. Image processing with ImageJ. Biophotonics Int. 11:36-42.

Achard, P., and Genschik, P. 2009. Releasing the brakes of plant growth: How GAs shutdown DELLA proteins. J. Exp. Bot. 60:1085-1092.

Achard, P., Cheng, H., De Grauwe, L., Decat, J., Schoutteten, H., Moritz, T., Van der Straeten, D., Peng, J. R., and Harberd, N. P. 2006. Integration of plant responses to environmentally activated phytohormonal signals. Science 311:91-94.

Achard, P., Gong, F., Cheminant, S., Alioua, M., Hedden, P., and Genschik, P. 2008. The cold-inducible CBF1 factor-dependent signaling pathway modulates the accumulation of the growth repressing DELLA proteins via its effect on gibberellin metabolism. Plant Cell 20:21172129

Albrecht, C., Boutrot, F., Segonzac, C., Schwessinger, B., GimenezIbanez, S., Chinchilla, D., Rathjen, J. P., De Vries, S. C., and Zipfel, C. 2012. Brassinosteroids inhibit pathogen-associated molecular patterntriggered immune signalling independent of the receptor kinase BAK1. 
Proc. Natl. Acad. Sci. U.S.A. 109:303-308.

Ali, S. S., Kumar, G. B. S, Khan, M., and Doohan, F. M. 2013. Brassinosteroid enhances resistance to Fusarium diseases. Phytopathology 103:1260-1267.

Bai G. H., and Shaner, G. 2004. Management and resistance in wheat and barley to Fusarium head blight. Annu. Rev. Phytopathol. 42:135-161.

Barbieri, M., Marcel, T. C., Niks, R. E., Francia, E., Pasquariello, M., Mazzamurro, V., Garvin, D. F., and Pecchioni, N. 2012. QTLs for resistance to the false brome rust Puccinia brachypodii in the model grass Brachypodium distachyon L. Genome 55:152-163.

Bari, R., and Jones, D. G. J. 2009. Role of plant hormones in plant defence responses. Plant Mol. Biol. 69:473-488.

Beccari, G., Covarelli, L., and Nicholson, P. 2011. Infection processes and soft wheat response to root rot and crown rot caused by Fusarium culmorum. Plant Pathol. 60:671-684.

Belkhadir, Y., Jailais, Y., Epple, P., Balsemão-Pires, E., Dangl, J. L., and Chory, J. 2012. Brassinosteroids modulate the efficiency of plant immune response to microbe-associated molecular patterns. Proc. Natl. Acad. Sci. U.S.A. 109:297-302.

Blein, M., Levrel, A., Lemoine, J., Gautier, V., Chevalier, M., and Barloy, D. 2009. Oculimacula yallundae lifestyle revisited: Relationships between the timing of eyespot symptom appearance, the development of the pathogen and the responses of infected partially resistant wheat plants. Plant Pathol. 58:1-11.

Both, M., Csukai, M., Stumpf, M. P. H., and Spanu, P. D. 2005. Gene expression profiles of Blumeria graminis indicate dynamic changes to primary metabolism during development of an obligate biotrophic pathogen. Plant Cell 17:2107-2122.

Bottalico, A., and Perrone, G. 2002. Toxigenic Fusarium species and mycotoxins associated with head blight in small-grain cereals in Europe. Eur. J. Plant Pathol. 108:611-624

Boyd, L. A., Smith, P. H., Green, R. M., and Brown, J. K. M. 1994. The relationship between the expression of defense-related genes and mildew development in barley. Mol. Plant-Microbe Interact. 7:401-410.

Bragg, J. N., Wu, J., Gordon, S. P., Guttman, M. E., Thilmony, R., Lazo, G. R., Gu, Y. Q., and Vogel, J. P. 2012. Generation and characterization of the Western Regional Research Center Brachypodium T-DNA insertional mutant collection. PLoS One 7:e41916. doi:10.1371/journal. pone.0041916. Published online.

Brown, J. K. M., and Wolfe, M. S. 1990. Structure and evolution of a population of Erysiphe-graminis f. sp. hordei. Plant Pathol. 39:376-390.

Brown, N. A., Urban, M., Van de Meene, A. M. L., and HammondKosack, K. E. 2010. The infection biology of Fusarium graminearum: Defining the pathways of spikelet to spikelet colonisation in wheat ears. Fungal Biol. 114:555-571.

Burt, C., Hollins, T. W., Powell., N, and Nicholson, P. 2010. Differential seedling resistance to the eyespot pathogens Oculimacula yallundae and Oculimacula acuformis, conferred by Pch2 in wheat and among accessions of Triticum monococcum. Plant Pathol. 59:819-828.

Chandler, P. M., Marion-Poll, A., Ellis, M., and Gubler, F. 2002. Mutants at the Slender1 locus of barley cv. Himalaya. Molecular and physiological characterization. Plant Physiol. 129:181-190.

Chapman, N. H., Burt, C., Dong, H., and Nicholson, P. 2008. The development of PCR based markers for the selection of eyespot resistance genes Pch1 and Pch2. Theor. Appl. Genet. 117:425-433.

Chen, G. D., Liu, Y. X., Wei, Y. M., McIntyre, C. L., Zhou, M. X., Zheng, Y. L., and Liu, C. J. 2013. Major QTL for Fusarium crown rot resistance in a barley landrace. Theor. Appl. Genet. 126:2511-2520.

Chen, G. D., Yan, W., Liu, Y., Wei, Y. M., Zhou, M. X., Zheng, Y. L., Manners, J. M., and Liu, C. J. 2014. The non-gibberellic acid-responsive semi-dwarfing gene uzu affects Fusarium crown rot resistance in barley. BMC Plant Biol. 14:22. doi:10.1186/1471-2229-14-22. Published online.

Chen, X., Steed, A., Travella, S., Keller, B., and Nicholson, P. 2009 Fusarium graminearum exploits ethylene signalling to colonize dicotyledonous and monocotyledonous plants. New Phytol. 182:975-983.

Chono, M., Honda, I., Zeniya, H., Yoneyama, K., Saisho, D., Takeda, K., Takatsuto, S., Hoshino, T., and Watanabe, Y. 2003. A semi dwarf phenotype of barley uzu results from a nucleotide substitution in the gene encoding a putative brassinosteroid receptor. Plant Physiol. 133:12091219.

Clouse S. D., Langford, M., and McMorris, T. C. 1996. A brassinosteroid insensitive mutant in Arabidopsis thaliana exhibits multiple defects in growth and development. Plant Physiol. 111:671-678.

Dalmais, M., Antelme, S., Ho-Yue-Kuang, S., Wang, Y., Darracq, O., Bouvier d'Yvoire, M., Cézard, L., Légée, F., Blondet, E., Oria, N., Troadec, C., Brunaud, V., Jouanin, L., Höfte, H., Bendahmane, A., Lapierre, C., and Sibout, R. 2013. A TILLING Platform for Functional Genomics in Brachypodium distachyon. PLoS One 8:e65503. doi: 10.1371/journal.pone.0065503. Published online.
De Vleesschauwer, D., Van Buyten, E., Satoh, K., Balidion, J., Mauleon, R., Choi, I. R., Vera-Cruz, C., Kikuchi, S., and Höfte, M. 2012. Brassinosteroids antagonize gibberellin- and salicylate-mediated root immunity in rice. Plant Physiol. 158:1833-1846.

De Vleesschauwer, D., Gheysen, G., and Hofte, M. 2013. Hormone defense networking in rice: Tales from a different world. Trends Plant Sci. 18:555-565.

Draper, J., Mur, L. A. J., Jenkins, G., Ghosh-Biswas, G. C., Bablak, P. Hasterok, R., and Routledge, A. P. M. 2001. Brachypodium distachyon. A new model system for functional genomics in grasses. Plant Physiol. 127:1539-1555.

Fan, M., Bai, M. Y., Kim, J. G., Wang, T., Oh, E., Chen, L., Park, C. H., Son, S. H., Kim, S. K., Mudgett, M. B., and Wang, Z. Y. 2014. The bHLH transcription factor HBI1 mediates the trade-off between growth and pathogen-associated molecular pattern-triggered immunity in Arabidopsis. Plant Cell 26:828-841.

Freeman, J., and Ward, E. 2004. Gaeumannomyces graminis, the take-all fungus and its relatives. Mol. Plant Pathol. 5: 235-252.

Glazebrook, J. 2005. Contrasting mechanisms of defense against biotrophic and necrotrophic pathogens. Annu. Rev. Phytopathol. 43:205227.

Honda, I., Zeniya, H., Yoneyama, K., Chono, M., Kaneko, S., and Watanabe, Y. 2003. Uzu mutation in barley (Hordeum vulgare L.) reduces the leaf unrolling response to brassinolide. Biosci. Biotechnol. Biochem. 67:1194-1197.

Huo, N., Vogel, J. P., Lazo, G. R., You, F. M., Ma, Y., McMahon, S., Dvorak, J., Anderson, O. D., Luo, M. C., and Gu, Y. Q. 2009. Structural characterization of Brachypodium genome and its syntenic relationship with rice and wheat. Plant Mol. Biol. 70:47-61.

International Brachypodium Initiative. 2010. Genome sequencing and analysis of the model grass Brachypodium distachyon. Nature 463:763768.

Jarosch, B., Jansen, M., and Schaffrath, U. 2003. Acquired resistance functions in mlo barley, which is hypersusceptible to Magnaporthe grisea. Mol. Plant-Microbe Interact. 16:107-114.

Kim, T. W., and Wang, Z. Y. 2010. Brassinosteroid signal transduction from receptor kinases to transcription factors. Annu. Rev. Plant Biol. 61:681-704.

Kliebenstein, D. J., and Rowe, H. C. 2008. Ecological costs of biotrophic versus necrotrophic pathogen resistance, the hypersensitive response and signal transduction. Plant Sci. 174:551-556.

Knight, N. L., and Sutherland, M. W. 2013. Histopathological assessment of wheat seedling tissues infected by Fusarium pseudograminearum Plant Pathol. 62:679-687.

Koh, S., Lee, S. C., Kim, M. H., Koh, J. H., Lee, S., An, G., Choe, S., and Kim, S. R. 2007. T-DNA tagged knockout mutation of rice $O s G S K 1$, an orthologue of Arabidopsis BIN2, with enhanced tolerance to various abiotic stresses. Plant Mol. Biol. 65:453-466.

León, J., Rojo, E., and Sánchez-Serrano, J. J. 2001. Wound signalling in plants. J. Exp. Bot. 52:1-9.

Lozano-Durán, R., Macho, A. P., Boutrot, F., Segonzac, C., Somssich, I. E., and Zipfel, C. 2013. The transcriptional regulator BZR1 mediates trade-off between plant innate immunity and growth. Elife 2:e00983. doi:10.7554/eLife.00983. Published online.

Makandar, R., Nalam, V., Chaturvedi, R., Jeannotte, R., Sparks, A. A., and Shah, J. 2010. Involvement of salicylate and jasmonate signalling pathways in Arabidopsis interaction with Fusarium graminearum. Mol. Plant-Microbe Interact. 23:961-970.

Makepeace, J. C., Havis, N. D., Burke, J. I., Oxley, S. J. P., and Brown, J. K. M. 2008. A method of inoculating barley seedlings with Ramularia collo-cygni. Plant Pathol. 57:991-999.

Malinovsky, F. G., Batoux, M., Schwessinger, B., Youn, J. H., Stransfeld, L., Win, J., Kim, S. K., and Zipfel, C. 2014. Antagonistic regulation of growth and immunity by the Arabidopsis basic helix-loop-helix transcription factor homolog of brassinosteroid enhanced expression 2 interacting with increased leaf inclination binding bHLH1. Plant Physiol. 164:1443-1455.

Miedaner, T. 1997. Breeding wheat and rye for resistance to Fusarium diseases. Plant Breed. 116:201-220.

Moseman, J. G., Macer, R. C. F., and Greeley, L. W. 1965. Genetic studies with cultures of Erysiphe graminis f. sp. hordei virulent on Hordeum spontaneum. Trans. Br. Mycol. Soc. 48:479-489.

Nahar, K., Kyndt, T., Hause, B., Höfte, M., and Gheysen, G. 2013. Brassinosteroids suppress rice defense against root-knot nematodes through antagonism with jasmonate pathway. Mol. Plant-Microbe Interact. 26:106-115.

Nakashita, H., Yasuda, M., Nitta, T., Asami, T., Fujioka, S., Arai, Y., Sekimata, K., Takatsuto, S., Yamaguchi, I., and Yoshida, S. 2003. Brassinosteroid functions in a broad range of disease resistance in tobacco and rice. Plant J. 33:887-898. 
Nam, K. H., and Li, J. 2002. BRI1/BAK1, a receptor kinase pair mediating brassinosteroid signalling. Cell 110:203-212.

Navarro, L., Bari, R., Achard, P., Lison, P., Memri, A., Harberd, N. P., and Jones, J. D. G. 2008. DELLAs control plant immune responses by modulating the balance and salicylic acid signalling. Curr. Biol. 18:650655

O’Donnell, P. J., Calvert, C., Atzorn, R., Wasternack, C., Leyser, H. M. O., and Bowles, D. J. 1996. Ethylene as a signal mediating the wound response of tomato plants. Science 274:1914-1917.

Parker, D., Beckmann, M., Enot, D. P., Overy, D. P., Rios, Z. C., Gilbert, M., Talbot, N., and Draper, J. 2008. Rice blast infection of Brachypodium distachyon as a model system to study dynamic host/pathogen interactions. Nat. Protocols 3:435-445.

Peng, J. R., Richards, D. E., Hartley, N. M., Murphy, G. P., Devos, K. M., Flintham, J. E., Beales, J., Fish, L. J., Worland, A. J., Pelica, F., Sudhakar, D., Christou, P., Snape, J. W., Gale, M. D., and Harberd, N. P. 1999. 'Green revolution' genes encode mutant gibberellins response modulators. Nature 400:256-261.

Peraldi, A., Beccari, G., Steed, A., and Nicholson, P. 2011. Brachypodium distachyon: A new pathosystem to study Fusarium head blight and other Fusarium diseases of wheat. BMC Plant Biol. 11:100.

Peraldi, A., Griffe, L. L., Burt, C., McGrann, G. R. D., and Nicholson, P. 2013. Brachypodium distachyon exhibits compatible interactions with Oculimacula spp. and Ramularia collo-cygni, providing the first pathosystem model to study eyespot and Ramularia leaf spot diseases. Plant Pathol. 5:35-41.

Robert-Seilaniantz, A., Grant, M., and Jones, J. D. G. 2011. Hormone crosstalk in plant disease and defense: More than just jasmonate-salicylate antagonism. Annu. Rev. Phytopathol. 49:317-343.

Routledge, A. P. M., Shelley, G., Smith, J. V., Talbot, N. J., Draper, J., and Mur, L. A. J. 2004. Magnaporthe grisea interactions with the model grass Brachypodium distachyon closely resemble those with rice (Oryza sativa). Mol. Plant Pathol. 5:253-265.

Saisho, D., Tanno, K., Chono, M., Honda, I., Kitano, H., and Takeda, K 2004. Spontaneous Brassinolide-insensitive barley mutants 'uzu' adapted to East Asia. Breed. Sci. 54:409-416.

Saville, R. J., Gosman, N., Burt, C. J., Makepeace, J., Steed, A., Corbitt, M., Chandler, E., Brown, J. K. M., Boulton, M. I., and Nicholson, P. 2012. The 'Green Revolution' dwarfing genes play a role in disease resistance in Triticum aestivum and Hordeum vulgare. J. Exp. Bot. 63:12711283.

Schroeder, H. W., and Christensen, J. J. 1963. Factors affecting resistance of wheat to scab caused by Gibberella zeae. Phytopathology 53:831-838.

Scott, P. R. 1971. The effect of temperature on eyespot (Cercosporella herporichoides) in wheat seedlings. Ann. Appl. Biol. 68:169-175.
Simpson, D. R., Rezanoor, H. N., Parry, D. W., and Nicholson, P. 2000. Evidence for differential host preference in Microdochium nivale var. majus and Microdochium nivale var. nivale. Plant Pathol. 49:261-268.

Stabentheiner, E., Minihofer, T., and Huss, H. 2009. Infection of barley by Ramularia collo-cygni: Scanning electron microscopic investigations. Mycopathologia 168:135-143.

Sun, T. P., and Gubler, F. 2004. Molecular mechanism of gibberellin signalling in plants. Annu. Rev. Phytopathol. 55:197-223.

Szekeres, M., Németh, K., Koncz-Kálmán, Z., Mathur, J., Kauschmann, A., Altmann, T., Rédei, G. P., Nagy, F., Schell, J., and Csaba, K. 1996. Brassinosteroids rescue the deficiency of CYP90, a cytochrome P450, controlling cell elongation and de-etiolation in Arabidopsis. Cell 85:171-182.

Thole, V., Peraldi, A., Worland, B., Nicholson, P., Doonan, J. H., and Vain, P. 2012. T-DNA mutagenesis in Brachypodium distachyon. J. Exp. Bot 63:567-576.

Tufan, H. A., McGrann, G. R. D., Magusin, A., Morel, J. B., Miché, L., and Boyd, L. A. 2009. Wheat blast: Histopathology and transcriptome reprogramming in response to adapted and nonadapted Magnaporthe isolates. New Phytol. 184:473-484.

Urashima, A. S., Lavorent, N. A., Goulart, A. C. P., and Mehta, Y. R. 2004. Resistance spectra of wheat cultivars and virulence diversity of Magnaporthe grisea isolates in Brazil. Fitopaol. Bras. 29:511-518.

Vain, P. 2011. Brachypodium as a model system for grass research. J. Cereal Sci. 54:1-7.

Vain, P., Worland, B., Thole, V., McKenzie, N., Alves, S. C., Opanowicz, M., Fish, L. J., Bevan, M. W., and Snape, J. W. 2008. Agrobacteriummediated transformation of the temperate grass Brachypodium distachyon (genotype Bd21) for T-DNA insertional mutagenesis. Plant Biotechnol. J. 6:941-941.

Xu, X. M., Monger, W., Ritieni, A., and Nicholson, P. 2007. Effect of temperature and duration of wetness during initial infection periods on disease development, fungal biomass and mycotoxin concentrations on wheat inoculated with single, or combinations of, Fusarium species. Plant Pathol. 56:943-956.

Yamamuro, C., Ihara, Y., Wu, X., Noguchi, T., Fujioka, S., Takatsuto, S., Ashikari, M., Kitano, H., and Matsuoka, M. 2000. Loss of function of a rice brassinosteroid insensitive 1 homolog prevents internode elongation and bending of the lamina joint. Plant Cell 12:1591-1605.

Zhao, J., Zheng, S. H., Fujita, K., and Sakai, K. 2004. Jasmonate and ethylene signalling and their interaction are integral parts of the elicitor signalling pathway leading to beta-thujaplicin biosynthesis in Cupressus lusitanica cell cultures. J. Exp. Bot.55:1003-1012.

Zhu, J. Y., Sae-Seaw, J., and Wang, Z. Y. 2013. Brassinosteroid signalling. Development 140:1615-1620. 